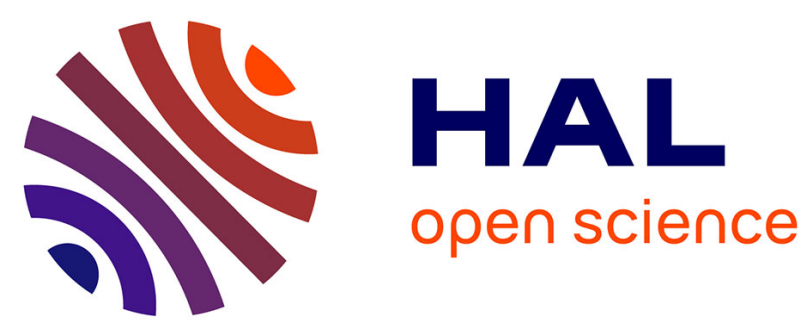

\title{
Polymer nanocomposites enhance S-nitrosoglutathione intestinal absorption and promote the formation of releasable nitric oxide stores in rat aorta
}

\author{
Wen Wu, Caroline Perrin-Sarrado, Hui Ming, Isabelle Lartaud, Philippe \\ Maincent, Xian-Ming Hu, Anne Sapin-Minet, Caroline Gaucher
}

\section{To cite this version:}

Wen Wu, Caroline Perrin-Sarrado, Hui Ming, Isabelle Lartaud, Philippe Maincent, et al.. Polymer nanocomposites enhance S-nitrosoglutathione intestinal absorption and promote the formation of releasable nitric oxide stores in rat aorta. Nanomedicine: Nanotechnology, Biology and Medicine, 2016, 12 (7), pp.1795-1803. 10.1016/j.nano.2016.05.006 . hal-01493332

\section{HAL Id: hal-01493332 \\ https://hal.univ-lorraine.fr/hal-01493332}

Submitted on 3 Apr 2019

HAL is a multi-disciplinary open access archive for the deposit and dissemination of scientific research documents, whether they are published or not. The documents may come from teaching and research institutions in France or abroad, or from public or private research centers.
L'archive ouverte pluridisciplinaire HAL, est destinée au dépôt et à la diffusion de documents scientifiques de niveau recherche, publiés ou non, émanant des établissements d'enseignement et de recherche français ou étrangers, des laboratoires publics ou privés. 
Dear Author,

Please, note that changes made to the HTML content will be added to the article before publication, but are not reflected in this PDF.

Note also that this file should not be used for submitting corrections. 


\title{
Polymer nanocomposites enhance $S$-nitrosoglutathione intestinal absorption and promote the formation of releasable nitric oxide stores in rat aorta
}

\author{
Wen Wu, PharmD, $\mathrm{PhD}^{\mathrm{a}}$, Caroline Perrin-Sarrado, PharmD, $\mathrm{PhD}^{\mathrm{a}}$, Hui Ming, PharmD ${ }^{\mathrm{a}}$, \\ Isabelle Lartaud, PharmD, $\mathrm{PhD}^{\mathrm{a}}$, Philippe Maincent, PharmD, $\mathrm{PhD}^{\mathrm{a}}$, Xian-Ming $\mathrm{Hu}, \mathrm{PhD}^{\mathrm{b}}$, \\ Anne Sapin-Minet, $\mathrm{PhD}^{\mathrm{a}}$, Caroline Gaucher, $\mathrm{PhD}^{\mathrm{a}, *}$
}

${ }^{a}$ CITHEFOR EA3452 "Drug targets, formulation and preclinical assessment", Faculté de Pharmacie, Université de Lorraine, Nancy, France

${ }^{\mathrm{b}}$ State Key Laboratory of Virology, Ministry of Education Key Laboratory of Combinatorial Biosynthesis and Drug Discovery, Wuhan University School of Pharmaceutical Sciences, Wuhan, China

Received 16 October 2015; accepted 5 May 2016

\section{Abstract}

Alginate/chitosan nanocomposite particles (GSNO-acNCPs), i.e. S-nitrosoglutathione (GSNO) loaded polymeric nanoparticles incorporated into an alginate and chitosan matrix, were developed to increase the effective GSNO loading capacity, a nitric oxide (NO) donor, and to sustain its release from the intestine following oral administration. Compared with free GSNO and GSNO loaded nanoparticles, GSNO-acNCPs promoted 2.7-fold GSNO permeation through a model of intestinal barrier (Caco-2 cells). After oral administration to Wistar rats, GSNO-acNCPs promoted NO storage into the aorta during at least $17 \mathrm{~h}$, as highlighted by (i) a long-lasting hyporeactivity to phenylephrine (decrease in maximum vasoconstrictive effect of aortic rings) and (ii) $\mathrm{N}$-acetylcysteine (a thiol which can displace $\mathrm{NO}$ from tissues)-induced vasodilation of aortic rings preconstricted with phenylephrine. In conclusion, GSNO-acNCPs enhance GSNO intestinal absorption and promote the formation of releasable NO stores into the rat aorta. GSNO-acNCPs are promising carriers for chronic oral application devoted to the treatment of cardiovascular diseases.

(C) 2016 Published by Elsevier Inc.

Key words: NO-donor; Polymer nanocomposites; Oral delivery; Isolated aorta vasoreactivity

In the cardiovascular system, deficiency of endogenous nitric oxide (NO) is the consequence of either insufficient synthesis (endothelium dysfunction) $^{1,2}$ or excessive NO degradation ${ }^{3,4}$ (increased oxidative or nitrosative stresses, decreased antioxidant enzyme activity). NO depletion is one of the key factors in the initiation and progress of many diseases, such as atherosclerosis, ${ }^{5}$ pulmonary hypertension, ${ }^{6}$ thrombosis, ${ }^{7}$

Funding and conflicts of interest: This work was supported by the 'Université de Lorraine and Région Lorraine'. W. Wu and H. Ming acknowledge Chinese Scholarships Council for their doctoral fellowships. X.-M. Hu was a guest professor at the Université de Lorraine, CITHEFOR EA 3452, for three months between 2014 and 2015.

The funders had no role in study design, data collection and analysis, decision to publish, or preparation of the manuscript.

*Corresponding author.

E-mail address: caroline.gaucher@univ-lorraine.f (C. Gaucher). ischemia ${ }^{8}$ and cardiac arrhythmia. ${ }^{9}$ To maintain an appropriate 31 level of $\mathrm{NO}$ and treat $\mathrm{NO}$ deficiency, several NO-related 32 therapeutics have been developed such as nitrosamines, organic 33 nitrates, metal-NO complexes, $\mathrm{N}$-diazeniumdiolates. However, 34 all act at very short term and lead to tolerance phenomena. 35 $S$-nitrosothiols (RSNOs) present the advantage of a longer 36 half-life, with no tolerance nor oxidative stress induction. Under 37 physiological conditions, $S$-nitrosoglutathione (GSNO), a major 38 endogenous RSNO, is one of the main storage forms of NO in 39 tissues. ${ }^{10}$ GSNO has been investigated for its powerful 40 antiplatelet activity, ${ }^{11,12}$ arterio/venous selective vasodilator 41 effects, ${ }^{13,14}$ antimicrobial ${ }^{15}$ and antithrombotic effects. ${ }^{16}$

Despite such therapeutic potencies, GSNO pharmaceutical 43 forms are still lacking. This may be related to the fast and often 44 unpredictable rate of decomposition of GSNO. In vitro, 45 because of $\mathrm{pH}$-, light- and temperature-dependent sensitivi- 46 ties, GSNO is susceptible to many degradation processes 47 
including $S$-NO bond homolysis, metal ion-catalyzed decomposition, and hydrolysis. In vivo, it is subjected to enzymes-induced decomposition such as GSNO reductase ${ }^{17}$ and carbonyl reductase $1 .{ }^{18}$ For this reason, the bioavailability of GSNO when administrated orally is limited. Two main strategies were described to overcome such limitations, through either inhibiting GSNO reductases activity ${ }^{19}$ or improving the stability of GSNO. In respect to the latter, many researchers focused on the protection of GSNO - during storage and in biological media - through the combination with delivery systems to promote pharmaceutical and medical applications. For instance, Seabra and co-workers dispersed GSNO into polyethylene glycol (PEG) ${ }^{20}$ or solid poly(vinyl alcohol)/poly(vinyl pyrrolidone) film ${ }^{21}$ to achieve the controlled release of $\mathrm{NO}$ adapted to topical application. de Mel and co-workers passively incorporated GSNO into a polyhedral oligomeric silsesquioxane poly(carbonate-urea)urethane (POSS-PCU) composite to produce a NO realizing implant for cardiovascular diseases treatment. ${ }^{22}$ Encapsulation followed by $S$-nitrosation of glutathione (GSH, the GSNO precursor) into mucoadhesive polymeric nanoparticles produced GSNO loaded nanoparticles, which slowed down GSNO decomposition at physiological temperature. ${ }^{23,24}$ Similarly, Shah et al described another way to prolong the release of NO by conjugating GSH on chitosan backbone and $S$-nitrosating the GSH thiol group. $^{25}$ In our previous work, polymeric nanoparticles based on poly(methyl)methacrylate were developed to load GSNO through direct encapsulation (GSNO-NP), which protect GSNO and preserve its availability during interaction with smooth muscle cells. ${ }^{26}$ However, the release profile we obtained was not long enough for chronic in vivo therapeutic applications. In our following work, ${ }^{27}$ we developed polymer nanocomposite particles (NCP), which refer to nanoparticles of nanometric size embedded in a polymer matrix forming a composite particle of micrometric size, as defined by Bhattacharya and coworkers. ${ }^{28}$ Microparticles were composed in our case of an alginate or a chitosan matrix including our previously described GSNO-NP. ${ }^{26}$ These GSNO-NPs embedded into chitosan or alginate nanocomposites increased the encapsulation efficiency of GSNO compared to GSNO-NPs (from $54 \%$ to $69 \%$ or $76 \%$, respectively) and sustained the in vitro release of GSNO until $24 \mathrm{~h}^{27}$

From these promising results, in the present study, our aims were to further improve GSNO oral bioavailability, to control its delivery at the absorption site and to prolong the residence time into the gastrointestinal tract, by combining both alginate plus chitosan in the matrix. Alginate and chitosan were chosen as mucoadhesive polymers increasing the residence time on the intestine mucus layer. ${ }^{29-32}$ As alginate has the capacity to penetrate the mucus layer, ${ }^{30}$ this will bring the drug closer to the intestinal cells, while chitosan exerts the property to open cells tight junction. ${ }^{31,32}$ Therefore, their combination will lead to increase drug permeability through the intestine. To broke new ground in the field of nanocomposite particles and merge mucopenetration and mucoadhesion properties in one system, we therefore developed GSNO-loaded alginate/chitosan nanocomposite particles (GSNO-acNCPs) formed through the incorporation of GSNO-NPs into a mix of alginate/chitosan matrix. The efficient encapsulation capacity and the sustained release profile 106 of GSNO encouraged us to further investigate GSNO perme- 107 ability through an intestinal cell barrier model (Caco-2). Finally, 108 for the first time, we administrated GSNO-acNCPs to Wistar rats 109 by gavage in order to evaluate their vascular effects, more 110 particularly their capacity to increase the NO-storage inside the 111 vascular wall.

\section{Methods}

Materials

All reagents were of analytical grade and all solutions prepared 115 with ultrapure deionized water $\left(>18.2 \mathrm{~m} \Omega . \mathrm{cm}\right.$ at $\left.25{ }^{\circ} \mathrm{C}\right)$. Sodium 116 nitrite was purchased from Merck (Germany). Acrylates/ 117 ammonium methacrylate copolymer (Eudragit ${ }^{\circledR}$ RL PO) was a 118 generous gift from Evonik industries (Germany). Alginate sodium, 119 chitosan (4-6 kDa), polyoxyethylene-polyoxypropylene block 120 copolymer (Pluronic ${ }^{\circledR}$ F-68), mucin from porcine stomach, HBSS 121 with $\mathrm{Ca}^{2+}$ and $\mathrm{Mg}^{2+}$ and all other reagents were obtained from 122 Sigma-Aldrich (France). All experiments and assays involving 123 GSNO were conducted under conditions of subdued light and 124 at $+4{ }^{\circ} \mathrm{C}$ in order to minimize light- and temperature-induced 125 GSNO degradation.

Methods

GSNO synthesis

GSNO was synthesized according to a previously described 129 method. ${ }^{33}$ Briefly, reduced GSH was incubated with an 130 equivalent of sodium nitrite under acidic condition (0.626 M 131 $\mathrm{HCl}$ ); after precipitation, the solid form of GSNO was obtained. 132 The purity of GSNO was assessed by HPLC and UV 133 spectrophotometry using the specific molar absorbance of the 134 $S$-NO bond at $334 \mathrm{~nm}\left(\varepsilon=922 \mathrm{M}^{-1} \mathrm{~cm}^{-1}\right)$.

Preparation of GSNO-loaded alginate/chitosan nanocomposite 136 particles

GSNO-loaded alginate/chitosan nanocomposite particles 138 (GSNO-acNCPs) were constituted by inner cores and external 139 polymer matrix. The inner cores were GSNO-loaded nano- 140 particles (GSNO-NP) prepared by a double emulsion (water- 141 oil-water) and solvent evaporation method as described in 142 previous work. ${ }^{26}$ Briefly, an aqueous solution containing 143 GSNO in $0.1 \%(\mathrm{w} / \mathrm{w})$ Pluronic ${ }^{\circledR}$ F-68 was emulsified by 144 sonication with an organic phase containing Eudragit ${ }^{\circledR}$ RL 145 PO $(100 \mathrm{mg} / \mathrm{mL}$ in dichloromethane). Then, sodium alginate 146 and sodium tripolyphosphate (TPP, $220 \mathrm{mg}$ ) were 147 fully dissolved in the resulting GSNO-NP suspension. 148 Over an ice bath, calcium chloride solution $\left(\mathrm{CaCl}_{2}, 2 \mathrm{M}\right) 149$ was added dropwise into this mixture to cross-link alginate 150 homogenized by sonication $(40 \mathrm{~W}$, ultrasonic processor, 151 France). GSNO-loaded alginate/chitosan nanocomposites 152 particles (GSNO-acNCPs) were finally formed by dropwise 153 addition of GSNO-NP-alginate mixture into the chitosan 154 solution ( $1 \mathrm{mg} / \mathrm{mL}$ in $1 \%(\mathrm{v} / \mathrm{v})$ acetic acid), under mechanical 155 stirring (1300 rpm) over ice bath. 


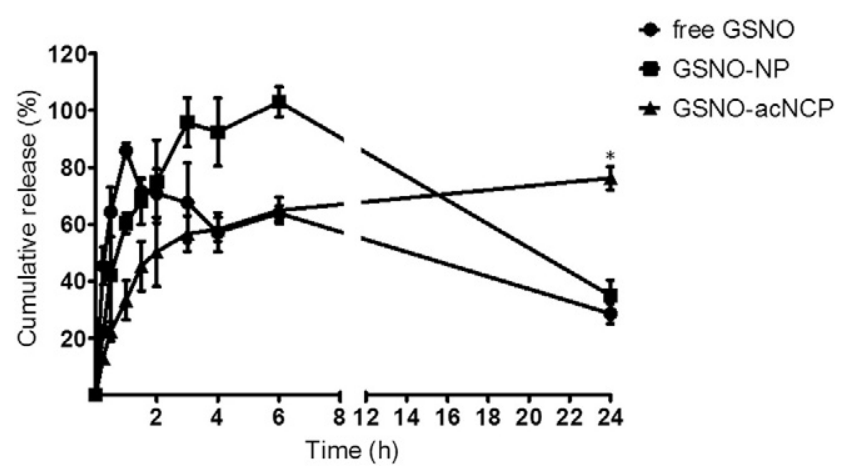

Figure 1. Release kinetic of the payload (GSNO and nitrite ions) from polymer nanocomposite particles in phosphate buffered saline $(0.148 \mathrm{M})$ at $37^{\circ} \mathrm{C}$. Data are shown as mean $\pm \mathrm{sd}, n=3 . *: P<0.05 v s$ free GSNO and GSNO-NP (two-way ANOVA). GSNO-NP: GSNO-loaded nanoparticles, GSNO-acNCPs: GSNO-loaded alginate/chitosan nanocomposite particles.

\section{Characterization of GSNO-loaded alginate/chitosan nanocomposite particles}

Determination of size. The volume particle size distribution of GSNO-acNCPs was determined by the laser diffraction method (Mastersizer 2000, Malvern Instruments, France). The GSNO-acNCPs were suspended in ultrapure water. The size of GSNO-acNCPs was described by the volume mean diameter measured in triplicate.

Evaluation of GSNO encapsulation efficiency. Encapsulation efficiency (EE) describes the quantity of the drug entrapped within GSNO-acNCPs compared with the initial drug amount. It was determined according to the following equation:

$E E=m_{e} / m_{i} \times 100$

where $\mathrm{EE}$ is the encapsulation efficiency in percent $(\%), m_{\mathrm{e}}$ is the mass of drug entrapped in particles, and $m_{\mathrm{i}}$ is the initial mass of drug. The entrapped drug within particles was evaluated by a two-step-liquid-liquid extraction. The external matrix of particles composed of sodium alginate and chitosan was disrupted by mechanical stirring followed by centrifugation and the amount of GSNO remaining in the supernatant, subtracted by the free nitrite ions quantified by the Griess assay, ${ }^{34}$ was quantified by the GriessSaville assay using sulfanilamide and $\mathrm{HgCl}_{2}$ in acidic conditions to cleave the $S$-NO bond, and $N$-(1-napthyl)ethylenediamine to form a chromophoric azo product that absorbs at $540 \mathrm{~nm}^{34}$

The resulting pellet, which corresponds to GSNO-NPs, was dissolved in $2 \mathrm{~mL}$ dichloromethane and the amount of GSNO in the nanoparticles was extracted in phosphate buffered saline (PBS) at pH 7.4 and determined by the Griess-Saville assay as described above. All the samples were prepared in triplicate.

Core loading expressed in $\mathrm{mg}$ of $\mathrm{GSNO} / \mathrm{g}$ of polymer was estimated from initial GSNO, Eudragit ${ }^{\circledR}$ RL PO, sodium alginate and chitosan amounts.

In vitro release kinetic. GSNO-acNCPs were suspended in $1 \mathrm{~mL}$ of PBS and were placed in cellulose dialysis tubing (average flat width $10 \mathrm{~mm}(0.4 \mathrm{in})$, cut-off $14 \mathrm{kDa})$. Release kinetic was measured as previously described ${ }^{27}$ in $200 \mathrm{~mL}$ of 192 PBS at $37{ }^{\circ} \mathrm{C}$ protected from light. The GSNO and nitrite ions 193 released were monitored every $30 \mathrm{~min}$ during two hours, every 194 hour from two to six hours, then at $24 \mathrm{~h}$, and immediately 195 quantified with a fluorometric method ${ }^{35}$ using diaminonaphtha- 196 lene (added or not with $\mathrm{HgCl}_{2}$ to cleave the $S$-NO bond) 197 producing naphthotriazole (emission $415 \mathrm{~nm} /$ excitation $375 \mathrm{~nm}, 198$ JASCO FP-8300, France).

Stability of GSNO in GSNO-loaded alginate/chitosan 200 nanocomposite particles. The GSNO-acNCP or GSNO-NP 201 suspensions were centrifuged $\left(15,000 \mathrm{~g}, 20 \mathrm{~min}, 4^{\circ} \mathrm{C}\right)$ and the 202 resulting pellets were kept in a freezer at $-20{ }^{\circ} \mathrm{C}$, in a fridge at 203 $+4{ }^{\circ} \mathrm{C}$ or at $+37^{\circ} \mathrm{C}$ in a humidified incubator. At predetermined 204 time intervals over 15 days (D) (1D, 2D, 3D, 4D, 5D and 15D), 205 the GSNO was extracted and analyzed by the Griess-Saville 206 assay as above to determine the remaining intact and decom- 207 posed GSNO. All the samples were prepared in triplicate. 208

Mucins binding assay

209

Changes in size and zeta potential of GSNO-NPs in contact 210 with a mucin dispersion were examined. ${ }^{36}$ After centrifugation 211 $\left(42,000 \mathrm{~g}, 30 \mathrm{~min}, 4^{\circ} \mathrm{C}\right.$; Heraeus Instruments, France), nano- 212 particles were resuspended in a mucin dispersion at a 213 concentration of $5 \mathrm{mg} / \mathrm{mL}$ polymer in $1 \mathrm{mg} / \mathrm{mL}$ mucin (ratio 214 5:1). The volume particle size distribution of GSNO-NPs was 215 determined by the laser diffraction method (Mastersizer 2000, 216 Malvern Instruments, France) and zeta potential was estimated 217 by electrophoretic mobility (ZetaSizer NanoZS, Malvern 218 Instruments, France).

Cytocompatibility

The cytocompatibility of GSNO-acNCPs was evaluated on 221 intestinal Caco-2 cells ATCC ${ }^{\circledR}$ HTB-37'TM . Caco-2 cells were 222 grown in complete medium consisting of Eagle's Minimum 223 Essential Medium EMEM supplemented with 20\% (v/v) fetal 224 bovine serum, $4 \mathrm{mM}$ of glutamine, $100 \mathrm{U} / \mathrm{mL}$ of penicillin, 225 $100 \mathrm{U} / \mathrm{mL}$ of streptomycin, $1 \%(\mathrm{v} / \mathrm{v})$ of non-essential amino 226 acids. Cells were cultivated at $37{ }^{\circ} \mathrm{C}$ under $5 \% \mathrm{CO}_{2}(\mathrm{v} / \mathrm{v})$ in a 227 humidified incubator. Caco-2 cells were seeded in 96-wells plates 228 at 20,000 cells/well $24 \mathrm{~h}$ before experiment. They were then 229 exposed to $0.5,1.0,5.0,10.0$ or $50.0 \mathrm{mg} / \mathrm{mL}$ of GSNO-acNCP for 230 $24 \mathrm{~h}$ at $37^{\circ} \mathrm{C}$, complete medium being used as control. 231 Cytocompatibility expressed by metabolic activity was checked 232 with the 3(4,5-dimethylthiazol-2-yl)-2,5-diphenyltetrazolium bro- 233 mide (MTT) assay. The absorbance of extracted formazan crystals 234 was read at $570 \mathrm{~nm}$ with a reference at $630 \mathrm{~nm}$ (EL 800235 microplate reader, Bio-TEK Instrument, Inc ${ }^{\circledR}$, France). Metabolic 236 activity in control condition was considered as $100 \%$. 237

In vitro cell permeability

238

The permeability of GSNO across the Caco-2 monolayer 239 was evaluated in the apical-to-basolateral direction in Hank's 240 Balanced Salt Solution (HBSS, pH 6.5). After seeding $10^{6} 241$ cells on cell culture inserts (Transwell ${ }^{\circledR}$, Corning, USA) with 242 $0.4 \mu \mathrm{m}$ pore size disposed in a 12 -wells plate, the medium 243 was replaced every two days during the first week and every 244 day during the lasting days until the differentiated cell 245 monolayer was formed (14-18 days, $588 \pm 44 \Omega / \mathrm{cm}^{2}$ ). For 246 

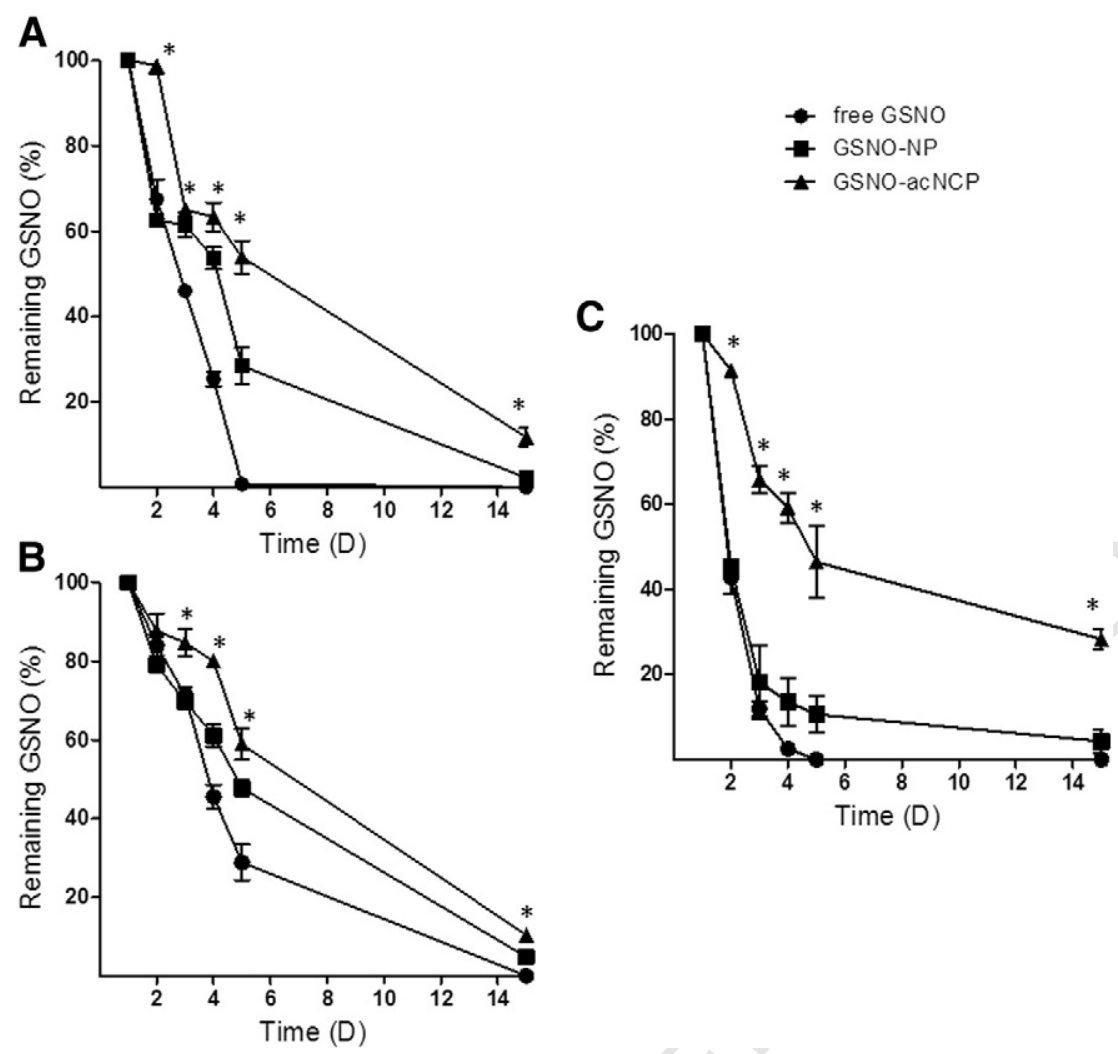

Figure 2. Stability of GSNO in polymer particles. GSNO-loaded alginate/chitosan nanocomposite particles (GSNO-acNCPs) or GSNO-loaded nanoparticles (GSNO-NP) suspensions were centrifuged and the resulting pellets were stored at $-20{ }^{\circ} \mathrm{C}(\mathbf{A}),+4{ }^{\circ} \mathrm{C}(\mathbf{B})$ and $+37^{\circ} \mathrm{C}(\mathbf{C})$ for 15 days. At regular intervals, the remaining intact GSNO was determined by the Griess-Saville assay. Data are expressed as mean $\pm \operatorname{sd}(n=3)$. * $P<0.05 v s$ free GSNO (two-way ANOVA).

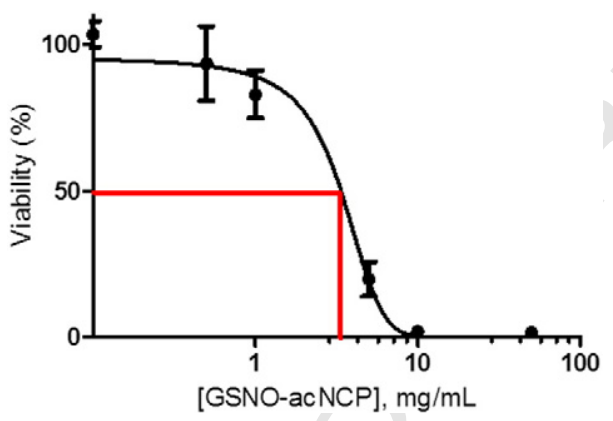

Figure 3. In vitro cytotoxicity of polymer nanocomposite particles on Caco-2 cells. Caco-2 cells were treated with the indicated concentrations of GSNO-loaded alginate/chitosan nanocomposite particles (GSNO-acNCPs) for $24 \mathrm{~h}$ at $37^{\circ} \mathrm{C}$. Viability was estimated through mitochondrial activity by the MTT assay. Data are expressed as mean $\pm \operatorname{sem}(n=3)$.

the permeation experiments, polymer nanocomposite particles containing $50 \mu \mathrm{M}$ of GSNO were suspended in $500 \mu \mathrm{L}$ of HBSS and introduced in the apical (donor) compartment, whereas, $1.5 \mathrm{~mL}$ of HBSS was placed in basolateral (receptor) compartment. After 1, 4 and $24 \mathrm{~h}$, each basolateral compartment was withdrawn and replaced with the same volume of fresh HBSS. The GSNO, nitrite and nitrate ions permeated and presented in basolateral (for each time) and apical (after $24 \mathrm{~h}$ only) compartments were detected using the fluorometric method. ${ }^{26}$
The integrity of the cell monolayer was checked before the 257 permeability studies by measuring the transepithelial electrical 258 resistance (TEER) using a Millicell ${ }^{\circledR}$-Electrical Resistance 259 system (Millipore, USA). In addition, the permeation of 260 fluorescein sodium $(5 \mu \mathrm{M})$ was also used to verify the integrity 261 of monolayer.

The cumulative amounts of GSNO crossing the Caco-2 263 monolayer were calculated from the concentrations measured in 264 basolateral compartments. The apparent permeability coefficient 265 (Papp) values were calculated using the following equation:

266

Papp $=\frac{d Q}{d t} \times \frac{1}{A \times C_{0}}$

$d Q / d t(\mathrm{~mol} / \mathrm{s})$ refers to the permeability rate (mol) of RSNO in 268 the basolateral compartment at the time of quantification, $A 269$ $\left(\mathrm{cm}^{2}\right)$ refers to membrane diffusion area, and $C_{0}(\mathrm{~mol} / \mathrm{mL})$ refers 270 to the initial concentration in the apical compartment. 271

The enhancement ratio (R) was calculated through the 272 following equation:

$\mathrm{R}=$ Papp $1 /$ Papp2

Papp1 refers to the apparent permeability coefficient of each 278 treatment, and Papp2 corresponds to the apparent permeability 277 coefficient of free GSNO. 
A

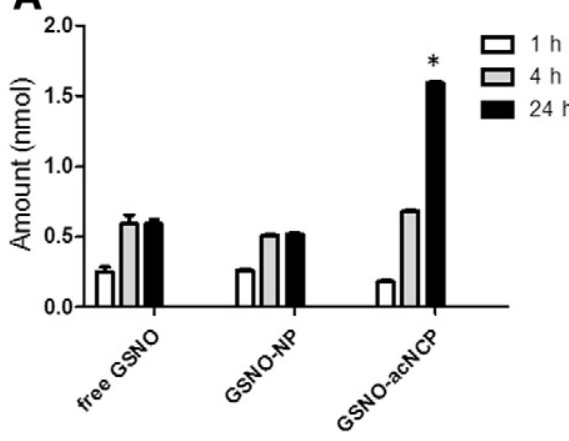

B

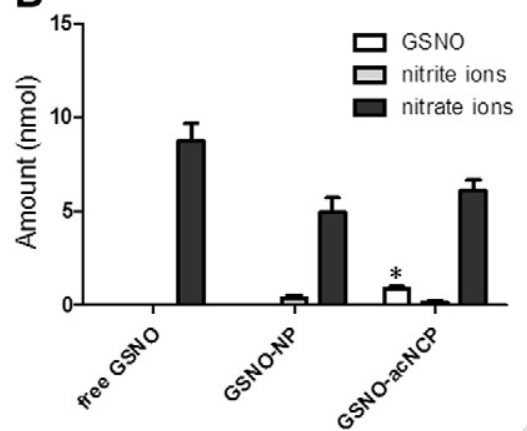

Figure 4. Caco-2 cell permeability of GSNO from polymer particles. Twenty five nmol of free GSNO or equivalent amount of GSNO-loaded nanoparticles (GSNO-NP) or GSNO-loaded alginate/chitosan nanocomposite particles (GSNO-acNCPs) were loaded in the apical compartment of a transwell ${ }^{\circledR}$ system seeded with Caco-2 cells 15 days before. (A) Amount of GSNO permeated from the apical to the basolateral compartment after $1 \mathrm{~h}, 4 \mathrm{~h}$ or $24 \mathrm{~h}$. (B) Amount of the different nitric oxide species remained in the apical compartment after $24 \mathrm{~h}$. Values presented have been corrected from control (cells without treatment for free GSNO, blank formulations for GSNO loaded formulations). Data are shown as mean \pm sem $(n=3)$. *: $P<0.05 v s$ free GSNO and GSNO-NP (two-way ANOVA).

\section{Ex vivo pharmacological evaluation}

Animals used and ethical statement. Vasorelaxation was evaluated on endothelium-removed aortic rings isolated from 12 week-old, male, normotensive, Wistar rats (Janvier Laboratories, Le Genest-St-Isle, France; 400-500 g). All experiments were performed in accordance with the European Community guidelines (2010/63/EU) for the use of experimental animals in the respect of the 3 Rs' requirements for Animal Welfare (C. Perrin-Sarrado permit number $n^{\circ} 54-72$, I. Lartaud $n^{\circ} 54-5$; the project untitled "Nitro-Vivo" was positively evaluated the19th of December 2014 by the CELMEA (regional ethical committee for animal experiments) and approved by the French Ministry of Research $\mathrm{n}^{\circ}$ APAFIS1614-2015090216575422v2). Animals were kept under standard conditions (temperature: $21 \pm 1{ }^{\circ} \mathrm{C}$, hygrometry $60 \pm 10 \%$, light on from 6 am to $6 \mathrm{pm}$ ) and had free access to standard diet (A04, Safe, Villemoisson-sur-Orge, France) and water (reverse osmosis system, Culligan, Brussells, Belgium).

Treatment schedule. GSNO-acNCPs $(15 \mathrm{mg}$ of GSNO $/ \mathrm{kg}$ body weight), free GSNO (15 $\mathrm{mg}$ of GSNO/kg body weight), blank-acNCPs or PBS as controls were administrated by gavage (10 mL/kg of rat) to Wistar rats (fasted $8 \mathrm{~h}$ before gavage). Seventeen hours after gavage, rats were sacrificed by exsanguination after anesthesia (sodium pentobarbitone $60 \mathrm{mg} / \mathrm{kg}$, intraperitoneal, Sanofi Santé Nutrition Animale, Libourne, France) and intravenous administration of heparin (500 U, Heparine Choay). A segment (around $3 \mathrm{~cm}$ ) of the descending thoracic aorta was removed and immediately placed in cold Krebs' solution. Vessels were cleaned from surrounding connective tissues and cut into $2-\mathrm{mm}$ long rings ( 8 rings per rat). The endothelium was removed by rubbing the intimal surface of the rings with forceps and immediately used for $e x$ vivo vasoactivity studies.

Measurement of vasoactivity. Aortic vasoactivity was measured using an isometric tension recording system in $10 \mathrm{~mL}$ organ chambers (EMKABATH, Emka Technology, France). 314 Baths were filled with Krebs' solution $\left(10 \mathrm{~mL}, 37{ }^{\circ} \mathrm{C}\right.$, pH 7.4) 315 and continuously bubbled with $95 \% \mathrm{O}_{2}$ and $5 \% \mathrm{CO}_{2}$. Following 316 60-min equilibration with a basal resting tension determined at 317 $2 \mathrm{~g}$, viability of aortic rings was assessed with potassium 318 chloride $\left(\mathrm{KCl}, 6 \times 10^{-2} \mathrm{M}\right)$ added in the baths. The contraction 319 rapidly reached a steady state and was expressed, after 15 min 320 exposure, as the developed tension from the basal resting tension 321 of $2 \mathrm{~g}$. Arteries showing less than $2.5 \mathrm{~g}$ of developed tension 322 were excluded. After viability test and a $30 \mathrm{~min}$ wash-out period so 323 that tension returns to baseline, aortic rings were tested with two 324 protocols: i) vasoconstriction of aortic rings ( $n=10-12$ per group, 325 from 4 different rats in each group) was measured with increasing 326 concentrations of phenylephrine (PHE) $\left(10^{-10} \mathrm{M}\right.$ to $\left.3 \times 10^{-5} \mathrm{M}\right)$; ii) 327 NO storage in the aorta was evaluated with $N$-acetylcysteine (NAC) 328 used to displace NO from cysteine-NO residue. Rings ( $n=10-12$ per 329 group, from 4 different rats in each group) preconstricted with $10^{-6} \mathrm{M} 330$ PHE, were added with NAC $\left(10^{-5} \mathrm{M}\right.$ and $\left.10^{-4} \mathrm{M}\right)$. Contractile 331 effects were expressed as induced developed tension (Delta T, g) and 332 relaxant ones in percentage of contraction $(100 \%$ being the stable 333 tension caused by $10^{-6} \mathrm{M}$ PHE).

The absence of functional endothelium was confirmed by the 335 ability of carbachol $10^{-5} \mathrm{M}$, a muscarinic receptors agonist, to 336 induce less than $10 \%$ of relaxation on $10^{-6} \mathrm{M}$ PHE-preconstricted 337 aortic rings.

Results are shown as either mean \pm standard deviation (sd) or 340 mean \pm standard error of the mean (sem) values. The half 341 maximal effective concentration $\left(\mathrm{EC}_{50}\right)$ and maximal response 342 $\left(\mathrm{E}_{\max }\right)$ were calculated by fitting each concentration response 343 curve using the Hill logistic equation. For the comparison of 344 Papp, and that of $\mathrm{E}_{\max }$ and $\mathrm{EC}_{50}$ for PHE, statistical comparisons 345 were performed using the one-way ANOVA $(P<0.05) .346$ Other analyses were performed using the two-way ANOVA 347 $\left(P_{\text {treatment }}<0.05 ; P_{\text {time }}<0.05\right)$. Statistical analyses were per- 348 formed using the GraphPad Prism software (GraphPad Software 349 version 5.0, San Diego, USA). 
t1.1 Table 1

Apparent permeability coefficient (Papp) and enhancement ratio (R) of t1.2 GSNO permeation across Caco-2 monolayers.

\begin{tabular}{llcc}
\cline { 2 - 4 } $\mathrm{t} 1.3$ & Group & Papp $\left(10^{-8} \mathrm{~cm} / \mathrm{s}\right)$ & $\mathrm{R}$ \\
\cline { 2 - 4 } $\mathrm{t} 1.4$ & Free GSNO & $8.3 \pm 0.3$ & 1.0 \\
$\mathrm{t} 1.5$ & GSNO-NP & $7.7 \pm 3.1$ & 0.9 \\
$\mathrm{t} 1.6$ & GSNO-acNCPs & $34.1 \pm 1.5^{*}$ & 4.1 \\
\cline { 2 - 3 }
\end{tabular}

Data are shown as mean \pm sem, $n=3$. All data sets were compared to free GSNO. *: $P<0.05$ vs free GSNO (one-way ANOVA). GSNO-NP: GSNO-loaded nanoparticles, GSNO-acNCPs: GSNO-loaded alginate/chitosan nanocomposite particles.

\section{Results}

Physico-chemical characterization of GSNO-loaded alginatel chitosan nanocomposite particles

The average size of the developed nanocomposite particles was $56 \pm 15 \mu \mathrm{m}$ (mean $\pm \mathrm{sd} ; n=3$ ). GSNO was entrapped within the nanocomposite particles with a high encapsulation efficiency $(76 \pm 10 \%)$, corresponding to an estimated core loading of $15.0 \pm 1.9 \mathrm{mg}$ of $\mathrm{GSNO} / \mathrm{g}$ of polymer. The inner core of GSNO loaded nanoparticles presented an estimated core loading of $5.7 \mathrm{mg}$ of GSNO/g of polymer with a zeta potential of $+40 \pm 6 \mathrm{mV}$ and a mean diameter of $0.289 \pm 0.014 \mu \mathrm{m} .{ }^{26}$ As shown in Figure 1, $75 \pm 3 \%$ of free GSNO was released from the dialysis bag during the first hour. Similarly, GSNO-NPs showed a release profile with a burst release of $95 \pm 2 \%$ of the initially loaded GSNO within the first $3 \mathrm{~h}$. On the other hand, only $57 \pm$ $6 \%$ of GSNO was released from GSNO-acNCPs within $3 \mathrm{~h}$ and the remaining amount was released in a sustained way over the next $21 \mathrm{~h}$.

\section{Stability of GSNO in GSNO-loaded alginate/chitosan nanocomposite particles}

The stability of GSNO within the polymer nanocomposite particles was evaluated at $-20^{\circ} \mathrm{C},+4{ }^{\circ} \mathrm{C}$ and $+37{ }^{\circ} \mathrm{C}$. After 5 days of storage at $-20{ }^{\circ} \mathrm{C}$ or $+4{ }^{\circ} \mathrm{C}, 100 \pm 1 \%$ or $70 \pm 5 \%$ of free GSNO respectively, was decomposed (Figure 2, $A, B$ ). When incorporated into the polymer nanocomposite particles, $16 \pm 5 \%\left(-20^{\circ} \mathrm{C}\right)$ and $12 \pm 4 \%\left(+4^{\circ} \mathrm{C}\right)$ of intact GSNO was preserved for 15 days, showing improvement of GSNO stability. At $+37{ }^{\circ} \mathrm{C}$, GSNO degraded faster (Figure 2, C): $57 \pm 4 \%$ of free GSNO had decomposed within two days and $98 \pm 1 \%$ after 4 days. Polymer nanocomposite particles increased the life-time of GSNO as $46 \pm 9 \%$ and $12 \pm 4 \%$ of intact GSNO were detected on the 4 th and 15 th days respectively.

\section{Mucin binding assay}

The mucoadhesion property of the polymeric GSNO-NPs was also evaluated. The diameter of GSNO-NPs in contact with mucin dispersion immediately increased from $0.2 \pm 0.0 \mu \mathrm{m}$ to $18.2 \pm 3.2 \mu \mathrm{m}$ (100 times more) and estimated zeta potential value was divided per 3 (from $+54 \pm 4 \mathrm{mV}$ to $+18 \pm 5 \mathrm{mV}$, (mean $\pm \mathrm{sd} ; n=3)$ ).

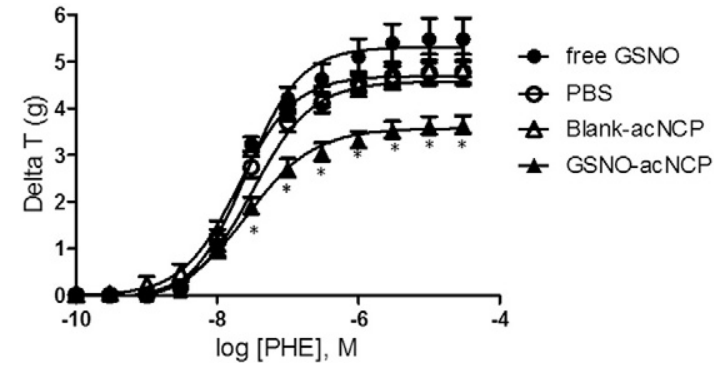

Figure 5. Contractile effect of phenylephrine (PHE) on aortic rings isolated from rats orally treated with free GSNO or GSNO-loaded polymer nanocomposite particles (GSNO-acNCPs) at $15 \mathrm{mg}$ of GSNO/ $\mathrm{kg}$ of body weight, $17 \mathrm{~h}$ before. Blank alginate/chitosan nanocomposite particles (Blank-acNCPs) and phosphate buffered saline (PBS) have been used as controls. Results are expressed as mean $\pm \operatorname{sem}(n=10-12$ per group, from 4 different rats in each group). *: $P<0.05$ vs PBS (two-way ANOVA).

Cytocompatibility and cell permeability

The concentration-response curve built from the MTT 391 metabolic activity assay (Figure 3 ) gave an $\mathrm{IC}_{50}$ at $3.24 \pm 392$ $0.38 \mathrm{mg} / \mathrm{mL}$ for GSNO-acNCPs. Therefore, a concentration of 393 $1 \mathrm{mg} / \mathrm{mL}$ (containing $50 \mu \mathrm{M}$ GSNO) that maintained $83 \pm 1 \% 394$ of cell viability was chosen for Caco-2 permeability studies. 395

Caco-2 cell monolayers were incubated with $50 \mu \mathrm{M} 396$ (representing $25 \mathrm{nmol}$ of GSNO in $0.5 \mathrm{~mL}$ ) free or 397 nanoparticle-associated GSNO in the apical compartment to 398 investigate GSNO permeability. After $1 \mathrm{~h}$ of incubation, a 399 similar concentration of GSNO was detected in the basolateral 400 compartment for all formulations (Figure 4, A). The 401 permeation kinetics of the RSNO were similar for GSNO 402 and GSNO-NPs: the amount transported rose rapidly to 403 $0.59 \pm 0.07 \mathrm{nmol}$ and $0.51 \pm 0.01 \mathrm{nmol}$, respectively, over 404 the first $4 \mathrm{~h}$, and then remained at a plateau up to $24 \mathrm{~h} .405$ GSNO-acNCPs showed a steady penetration rate over the 406 whole $24 \mathrm{~h}$, and promoted 2.7-fold more GSNO crossing the 407 cell monolayer than free GSNO or GSNO-NP (Figure 4, A). 408 The Papp value of GSNO (showing the ability of NPs and 409 acNCPs to help the transport of GSNO across Caco-2 cell 410 monolayer) did not change with NP, but significantly 411 increased after GSNO-NPs incorporation into nanocomposite 412 particles, showing an enhancement ratio of 4.1 (Table 1). In 413 contrast to free GSNO and GSNO-NPs, GSNO-acNCPs 414 retained $0.9 \pm 0.1 \mathrm{nmol}$ of intact GSNO in the apical 415 compartment after $24 \mathrm{~h}$ of incubation (Figure 4, B) showing 416 that GSNO-acNCPs could have an even longer release profile. 417

At the end of experiments, the test using the low molecular 418 weight hydrophilic tracer sodium fluorescein, showed that the 419 permeation of sodium fluorescein in the treated groups $(18 \pm 420$ $5 \%)$ was higher than the positive control $(6.1 \pm 0.5 \%)$ and less 421 than negative control $(32 \pm 9 \%)$, in which cells were treated with 422 HBSS without $\mathrm{Ca}^{2+}$ and $\mathrm{Mg}^{2+}$. Taken together, these results 423 confirmed the integrity of cells monolayer after incubation with 424 the GSNO-acNCPs with a slight opening of tight junction due to 425 chitosan.

GSNO-NPs ${ }^{26}$ showed a core loading two times under the 427 GSNO-acNCPs core loading (5.7 $\mathrm{mg}$ of $\mathrm{GSNO} / \mathrm{g}$ of polymer 428 
W. Wu et al / Nanomedicine: Nanotechnology, Biology, and Medicine $x x$ (2016) xxx-xxx

t2.1 Table 2

Half maximum effective concentration $\left(\mathrm{EC}_{50}\right)$ and maximum effect $\left(\mathrm{E}_{\max }\right)$ of

phenylephrine measured in isolated aortic rings.

\begin{tabular}{lll}
\hline Group & $\mathrm{EC}_{50}\left(10^{-8} \mathrm{M}\right)$ & $\mathrm{E}_{\max }(\mathrm{g})$ \\
\hline PBS & $3.1 \pm 0.1$ & $4.8 \pm 0.1$ \\
Blank-acNCPs & $1.9 \pm 0.2$ & $4.8 \pm 0.3$ \\
Free GSNO & $3.1 \pm 0.1$ & $4.9 \pm 0.1$ \\
GSNO-acNCPs & $3.1 \pm 0.1$ & $3.7 \pm 0.1^{*}$ \\
\hline
\end{tabular}

Data are shown as mean \pm sem, $(n=10-12$ per group, from 4 different rats in each group). *: $P<0.05$ vs PBS (one-way ANOVA). PBS: phosphate buffered saline. Blank-acNCPs: blank alginate/chitosan nanocomposite particles, GSNO-acNCPs: GSNO-loaded alginate/chitosan nanocomposite particles.

and $15.0 \pm 1.9 \mathrm{mg}$ of $\mathrm{GSNO} / \mathrm{g}$ of polymer, respectively). Furthermore, the permeability studies failed in showing a higher and long lasting absorption of GSNO for the GSNO-NPs through intestinal cells compared to free GSNO. For these two reasons, the GSNO-NPs were moved aside from the in vivo studies

\section{Pharmacological vascular effects}

The dose-response curves to PHE were similar in aortic rings from Wistar rats orally treated $17 \mathrm{~h}$ earlier with free GSNO, blank-acNCP or PBS (Figure 5). In aortic rings from rats treated with GSNO-acNCP (15 mg/kg body weight), the contractile maximal effect $\left(E_{\max }\right)$ of PHE significantly decreased (from $4.8 \mathrm{~g}$ in control groups to $3.7 \mathrm{~g}$ in the GSNO-acNCP group, $25 \%, P<0.05)$ with no change in $\mathrm{EC}_{50}$ (Table 2).

In all the control groups, NAC failed to relax the vessels. However, in the group treated with GSNO-acNCP, NAC induced significant relaxation $\left(11 \pm 1 \%\right.$ at $10^{-5} \mathrm{M}$ and $24 \pm$ $3 \%$ at $10^{-4} \mathrm{M}, P<0.05$ compared to controls, Figure 6 ).

\section{Discussion}

The encapsulation of the fragile molecule GSNO within drug delivery systems is still challenging. Different approaches, either through $S$-nitrosation of free or conjugated $\mathrm{GSH}^{23,25}$ or direct encapsulation of $\mathrm{GSNO}^{21,37}$ are described in the literature. In the present study, we adopted the second approach with gentle formulation process to develop polymer nanocomposite particles loaded with GSNO. The polymer nanocomposites were obtained by incorporation of GSNO loaded Eudragit ${ }^{\circledR}$ RL nanoparticles $(\text { GSNO-NP })^{26}$ into a polymer matrix prepared from a mixture of alginate and chitosan by ionic gelation. The challenge was to control the loading of GSNO within the nanocomposite particles in order to get potential pharmacological efficiency. We based our calculations on the minimal concentration of $\mathrm{NO}$ required to stimulate the synthesis of cyclic GMP by soluble guanylate cyclase in vascular smooth muscle (approximately $10 \mathrm{nmol} / \mathrm{L}^{38}$ ), and the dose of GSNO that significantly decreases mean arterial blood pressure (i.e. $3 \mathrm{mg}$; $100 \mu \mathrm{g} / \mathrm{min}$ for $30 \mathrm{~min}$, intravenous, in human ${ }^{39}$ ).

Compared to our previous published results on GSNO-NP, ${ }^{26}$ the newly formulated composite particles improved the loading capacity of GSNO by 2.6-fold (from 5.7 to $15.0 \mathrm{mg}$ of GSNO/g of polymer). This improvement can probably be attributed to the use of alginate and chitosan, which are hydrophilic and have good affinity for

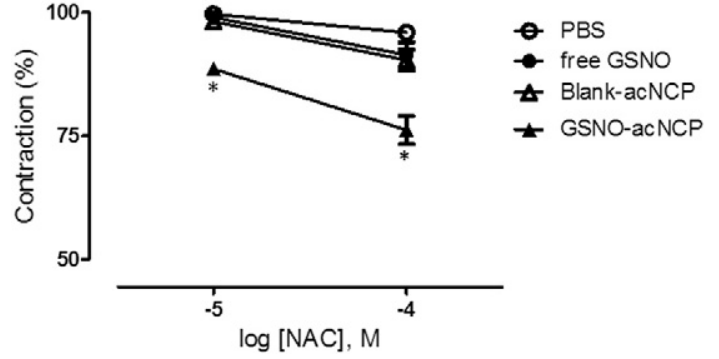

Figure 6. Vascular effect of $10^{-5} \mathrm{M}$ and $10^{-4} \mathrm{M} N$-acetylcysteine (NAC) on precontracted $\left(10^{-6} \mathrm{M}\right.$ phenylephrine) aortic rings isolated from rats orally treated with free GSNO or GSNO-loaded polymer nanocomposite particles (GSNO-acNCPs) at $15 \mathrm{mg}$ of GSNO/kg of body weight, $17 \mathrm{~h}$ before. Blank alginate/chitosan nanocomposite particles (Blank-acNCPs) and phosphate buffered saline (PBS) have been used as controls. Results are expressed as mean \pm sem ( $n=10-12$ per group, from 4 different rats in each group). *: $P<0.05 v s$ PBS (two-way ANOVA).

GSNO thus allowing the entrapment not only of GSNO-NP but also 469 of the free GSNO remaining outside the nanoparticles. This is 470 consistent with our previously reported polymer nanocomposites 471 based on chitosan or alginate separately. ${ }^{27} 472$

Our results on in vitro release demonstrate that the polymer 473 nanocomposite particles prevented the burst release of hydro- 474 philic GSNO observed with GSNO-NP alone. This is in 475 agreement with the results of Hasan et $\mathrm{al}^{40}$ showing that 476 composite particles were able to reduce the burst release. 477 GSNO-acNCPs present two polymer barriers to the diffusion of 478 GSNO: the first being formed by the hydrophobic Eudragit ${ }^{\circledR}$ RL 479 polymer and the second by the outer hydrophilic matrix 480 composed of chitosan and alginate. The combination of both 481 leads the diffusion distance to increase and the release rate to 482 slow down. Furthermore, as reported by de Seabra et $\mathrm{al}^{20,41,42} 483$ increased microviscosity of the solvent improve the stability of 484 RSNO. The presence of alginate and chitosan, which build a 485 hydrophilic matrix for the particles, increases the viscosity 486 thereby protecting GSNO from thermal decomposition and 487 improved GSNO stability. Moreover, the increased stability we 488 obtained at $+37^{\circ} \mathrm{C}$ for GSNO-acNCPs was in accordance with 489 our previous observations using alginate or chitosan in polymer 490 nanocomposite particles. ${ }^{27}$

GSNO-acNCPs also improved the permeability of GSNO 492 through the Caco-2 cells model, and increased the Papp value, a 493 marker of drug absorption. This permeation enhancement may 494 be attributed to three major factors: i) the positive charge of 495 GSNO-acNCPs (zeta potential approximately equal to $+18.5 \pm 496$ $0.8 \mathrm{mV}$ ), which allows electrostatic attraction with the nega- 497 tively charged cell membrane; ii) the composition of nanocom- 498 posite particles based on chitosan and alginate, which have 499 mucoadhesive properties and reinforce the interaction with cells; 500 iii) the high level of protection of GSNO afforded by the 501 nanocomposite particles. While we did not directly measure 502 GSNO crossing through intestinal tissue, our results augur a 503 promising oral delivery, for which intestinal absorption is one of 504 the key factors determining drug bioavailability. The mecha- 505 nisms involved in intestinal crossing remain to be evaluated. 506 However, the glycosidic bonds of chitosan were shown to be 507 rapidly hydrolyzed under gastric conditions, ${ }^{43}$ so only a portion 508 
of this polymer and the alginate of the complex matrix will be able to adhere on the mucus layer and to open tight junctions in the intestinal compartment. ${ }^{44}$ Moreover, alginate will help the inner core made of GSNO-NPs to penetrate the mucus layer. GSNO-NPs will no longer stay at the nanometer size: as we showed they adsorb proteins like mucins or albumin ${ }^{26}$ to reach a final size around $20 \mu \mathrm{m}$. Others also showed that the mucus layer strongly increase particle size and modify absorption of particles through the intestine. ${ }^{45}$ Indeed, Bajka et al demonstrated that a particle diameter higher than $500 \mathrm{~nm}$ largely decreased particles diffusion. ${ }^{45}$ Therefore, it is probable that only GSNO or other NO species will diffuse within the intestinal tight junctions, already opened by chitosan, and reach the vascular compartment.

Whatever the mechanisms involved in intestinal crossing, oral administration of GSNO-acNCPs to Wistar rats reveals NO-related vascular effects attesting that NO effectively reaches the blood stream. The decreased contractile response of aorta to PHE is the proof that the absorbed GSNO is transported from the intestine to the aortic wall by itself or through transnitrosation process of albumin or hemoglobin in the blood stream. Then, close to the vascular wall, transnitrosation processes occur again to generate a NO store inside the vascular wall. The final storage of NO in vascular smooth muscle cells was highlighted by aortic hyporeactivity to PHE and vasorelaxation in response to NAC. Indeed, in the absence of NO storage, NAC is not able to relax aortic rings, whereas, in presence of $\mathrm{NO}$ stores ( $S$-nitrosation of proteins/peptides cysteine residues) within the vessel wall, NAC after entering into the cells displaces NO from vascular stores, which finally activates the guanylate cyclase/GMPc pathway inducing relaxation. Finally, the transnitrosation reactions with $S$-nitrosated proteins/peptides, ${ }^{46}$ leading to the formation of unstable $S$-nitrosothiols may be involved, both in the storage processes during the 17 hours following gavage, and in the release of NO induced by NAC. ${ }^{47}$ Similar results were obtained ex vivo in previous experiments where NO donors applied directly on the aortic rings, sustained hyporeactivity to vasoconstrictors from 1 to 4 hours. ${ }^{47-50}$ Oral administrations of PBS or blank-acNCPs, as that of free GSNO - due to its limited stability - were unable to form a reservoir of NO in vascular tissue, and NAC has no vasorelaxant effect.

Another hypothesis for the decreased response to PHE may relate to the $S$-nitrosation of the alpha1-adrenergic receptor leading to its decreased affinity for sympathetic ligands. ${ }^{51}$ This is unlikely in the present study as $\mathrm{EC}_{50}$ remained similar in all groups of treatment.

In conclusion, we demonstrated the therapeutic potential of polymer nanocomposite particles based on poly(methyl)methacrylate inside an alginate plus chitosan matrix for oral delivery of GSNO. The efficient loading, protection and sustained release of GSNO provided by these formulations promote GSNO absorption through the intestinal barrier, allow GSNO to reach the blood stream and contribute to form a reservoir of NO by transnitrosation inside the vascular wall. Seventeen hours following oral administration, vascular hyporeactivity to the vasoconstrictor remained. These new drug delivery systems of NO donors may be particularly adapted for oral treatment of cardiovascular diseases.
Acknowledgments

The authors are grateful to Dr. François Dupuis, Patrick 568 Liminana and Isabelle Fries (EA 3452, CITHEFOR, Lorraine 569 University) for the helpful advices and technical support to 570 experimental studies, Pr Gillian Barratt (UMR CNRS 861, 571 Paris-Sud University) for manuscript spelling corrections.

\section{References}

1. Versari D, Daghini E, Virdis A, Ghiadoni L, Taddei S. Endothelium- 574 dependent contractions and endothelial dysfunction in human hyper- 575 tension. Pharmacol 2009;157:527-36, http://dx.doi.org/10.1111/ 576 j.1476-5381.2009.00240.x.

2. Davignon J, Ganz P. Role of endothelial dysfunction in atherosclerosis. 578 Circulation 2004;109:27-32, http://dx.doi.org/10.1161/579 01.CIR.0000131515.03336.f8.

3. Moncada S, Palmer RM, Higgs EA. Nitric oxide: Physiology, 581 pathophysiology, and pharmacology. Pharmacol Rev 1991;43:109-42 582 [doi:0031-6997/91/4302-0109\$03.00/0].

4. Cai H, Harrison DG. Endothelial dysfunction in cardiovascular diseases: 584 The role of oxidant stress. Circ Res 2000;87:840-4, http://dx.doi.org/ 585 10.1161/01.RES.87.10.840.

5. Napoli C, de Nigris F, Williams-Ignarro S, Pignalosa O, Sica V, Ignarro 587 LJ. Nitric oxide and atherosclerosis: An update. Nitric Oxide 588 2006; 15:265-79.

6. Sim Ji-Yeon. Nitric oxide and pulmonary hypertension. Anesthesiol 590 2010;58:4-14, http://dx.doi.org/10.4097/kjae.2010.58.1.4. 591

7. Loscalzo J. Nitric oxide insufficiency, platelet activation, and arterial 592 thrombosis. Circ Res 2001;88:756-62, http://dx.doi.org/10.1161/ 593 hh0801.089861.

8. Bolaños JP, Almeida A. Roles of nitric oxide in brain hypoxia-ischemia. 595 Biochim Biophys Acta 1999;1411:415-36, http://dx.doi.org/10.1016/596 S0005-2728(99)00030-4.

9. Tamargo J, Caballero R, Gómez R, Delpón E. Cardiac electrophysio- 598 logical effects of nitric oxide. Cardiovasc Res 2010;87:593-600, http:// 599 dx.doi.org/10.1093/cvr/cvq214.

10. Hogg N, Singh RJ, Kalyanaraman B. The role of glutathione in the 601 transport and catabolism of nitric oxide. FEBS Lett 1996;382:223-8, 602 http://dx.doi.org/10.1016/0014-5793(96)00086-5.

11. Riccio DA, Dobmeier KP, Hetrick EM, Privett BJ, Paul HS, Schoenfisch 604 MH. Nitric oxide-releasing $S$-nitrosothiol-modified xerogels. Biomater- 605 ials 2009;30:4494-502, http://dx.doi.org/10.1016/606 j.biomaterials.2009.05.006.

12. Langford EJ, Brown AS, Wainwright RJ, de Belder AJ, Thomas MR, 608 Smith RE, et al. Inhibition of platelet activity by $S$-nitrosoglutathione 609 during coronary angioplasty. Lancet 1994;344:1458-60, http:// 610 dx.doi.org/10.1016/S0140-6736(94)90287-9.

13. MacAllister RJ, Calver AL, Riezebos J, Collier J, Vallance P. Relative 612 potency and arteriovenous selectivity of nitrovasodilators on human 613 blood vessels: An insight into the targeting of nitric oxide delivery. $J 614$ Pharmacol Exp Ther 1995;273:154-60.

14. Rassaf T, Kleinbongard P, Preik M, Dejam A, Gharini P, Lauer T, et al. 616 Plasma nitrosothiols contribute to the systemic vasodilator effects of 617 intravenously applied NO: Experimental and clinical study on the fate of 618 NO in human blood. Circ Res 2002;91:470-7, http://dx.doi.org/10.1161/ 619 01.RES.0000035038.41739.CB.

15. Friedman AJ, Blecher K, Schairer D, Tuckman-Vernon C, Nacharaju P, 621 Sanchez D, et al. Improved antimicrobial efficacy with nitric oxide 622 releasing nanoparticle generated $S$-nitrosoglutathione. Nitric Oxide 623 2011;25:381-6, http://dx.doi.org/10.1016/j.niox.2011.09.001.

16. Sorragi Cde L, Shishido SM, Lemos ME, Marcondes S, Antunes E, 625 Krieger MH. In vitro evaluation of the safe margin, antithrombotic and 626 antiproliferative actions for the treatment of restenosis: Nitric oxide 627 
donor and polymers. Cell Biochem Funct 2011;29:207-14, http:// dx.doi.org/10.1002/cbf.1738.

17. Jensen DE, Belka GK, Du Bois GC. S-Nitrosoglutathione is a substrate for rat alcohol dehydrogenase class III isoenzyme. Biochem $J$ 1998;331(Pt 2):659-68.

18. Bateman RL, Rauh D, Tavshanjian B, Shokat KM. Human carbonyl reductase 1 is an $S$-nitrosoglutathione reductase. $J$ Biol Chem 2008;283:35756-62, http://dx.doi.org/10.1074/jbc.M807125200.

19. Chen Q, Sievers RE, Varga M, Kharait S, Haddad DJ, Patton AK, et al. Pharmacological inhibition of $S$-nitrosoglutathione reductase improves endothelial vasodilatory function in rats in vivo. J Appl Physiol 2013;114:752-60, http://dx.doi.org/10.1152/japplphysiol.01302.2012.

20. Seabra AB, de Souza GF, da Rocha LL, Eberlin MN, de Oliveira MG. SNitrosoglutathione incorporated in poly(ethylene glycol) matrix: Potential use for topical nitric oxide delivery. Nitric Oxide 2004;11:263-72, http://dx.doi.org/10.1016/j.niox.2004.09.005.

21. Seabra AB, da Rocha LL, Eberlin MN, de Oliveira MG. Solid films of blended poly(vinyl alcohol)/poly(vinyl pyrrolidone) for topical $S$ nitrosoglutathione and nitric oxide release. J Pharm Sci 2005;94:9941003, http://dx.doi.org/10.1002/jps.20314.

22. de Mel A, Naghavi N, Cousins BG, Clatworthy I, Hamilton G, Darbyshire A, et al. Nitric oxide-eluting nanocomposite for cardiovascular implants. J Mater Sci Mater Med 2014;25:917-29, http:// dx.doi.org/10.1007/s10856-013-5103-2.

23. Marcato PD, Adami LF, de Melo Barbosa R, Melo PS, Ferreira IR, de Paula L, et al. Development of a sustained-release system for nitric oxide delivery using alginate/chitosan nanoparticles. Curr Nanosci 2013;9:1-7, http://dx.doi.org/10.2174/157341313805117848.

24. Marcato PD, Adami LF, Melo PS, de Paula L, Durán N, Seabra AB. Glutathione and $S$-nitrosoglutathione in alginate/chitosan nanoparticles: Cytotoxicity. JPCS 2011;304:012045, http://dx.doi.org/10.1088/17426596/304/1/012045.

25. Shah SU, Martinho N, Socha M, Pinto Reis C, Gibaud S. Synthesis and characterization of $S$-nitrosoglutathione-oligosaccharide-chitosan as a nitric oxide donor. Expert Opin Drug Deliv 2015;12:1-15, http:// dx.doi.org/10.1517/17425247.2015.1028916.

26. Wu W, Gaucher C, Diab R, Fries I, Xiao YL, Hu XM, et al. Time lasting $S$-nitrosoglutathione polymeric nanoparticles delay cellular protein $S$ nitrosation. Pharm Biopharm 2015;89:1-8, http://dx.doi.org/10.1016/ j.ejpb.2014.11.005.

27. Wu W, Gaucher C, Fries I, Hu XM, Maincent P, Sapin-Minet A. Polymer nanocomposite particles of $S$-nitrosoglutathione: A suitable formulation for protection and sustained oral delivery. Pharm 2015;495:354-61, http://dx.doi.org/10.1016/j.ijpharm.2015.08.074

28. Bhattacharya SN, Kamal MR, Gupta RK. Polymeric Nanocomposites: Theory and Practice. Carl Hanser Verlag GmbH \& Co. KG978-3-44640270-6; 20071-13.

29. Gomez-Orellana I. Strategies to improve oral drug bioavailability. Expert Opin Drug Deliv 2005;2:419-33, http://dx.doi.org/10.1517/ 17425247.2.3.419.

30. Zhang H, Zhang J, Streisand JB. Oral mucosal drug delivery: Clinical pharmacokinetics and therapeutic applications. Clin Pharmacokinet 2002;41:661-80, http://dx.doi.org/10.2165/00003088-20024109000003.

31. Dodane V, Amin Khan M, Merwin JR. Effect of chitosan on epthelial permeability and structure. Pharm 1999;182:21-32.

32. Thanou M, Verhoef JC, Junginger HE. Oral drug absorption enhancement by chitosan and its derivatives. Adv Drug Deliv Rev 2001;52:117-26, http://dx.doi.org/10.1016/S0169-409X(01)00231-9.

33. Parent M, Dahboul F, Schneider R, Clarot I, Maincent P, Lerroy P, et al. A complete physicochemical identity card of $S$-nitrosoglutathione. Curr Pharm Anal 2013;9:31-42.

34. Sun J, Zhang X, Broderick M, Fein H. Measurement of nitric oxide production in biological systems by using griess reaction assay. Sensors 2003;3:276-84, http://dx.doi.org/10.3390/s30800276.
35. Liu CY, Zhao M, Ren CY, YANG GP, Li PF, Han Y. Direct 693 measurement of nitric oxide in seawater medium by fluorometric 694 method. Anal Chem 2009;37:1463-7, http://dx.doi.org/10.1016/S1872- 695 2040(08)60136-X.

36. Lim JH, You SK, Baek JS, Hwang CJ, Na YG, Shin SC, et al. 697 Preparation and evaluation of polymeric microparticulates for improving 698 cellular uptake of gemcitabine. Nanomedicine 2012;7:2307-14, http:// 699 dx.doi.org/10.2147/IJN.S30465.

37. Parent M, Boudier A, Fries I, Gostyńska A, Rychter M, Lulek J. Nitric 701 oxide-eluting scaffolds and their interaction with smooth muscle cells in 702 vitro. J Biomed Mater Res A 2015;103:3303-11, http://dx.doi.org/ 703 10.1002/jbm.a.35464.

38. Hutchinson PJ, Palmer RM, Moncada S. Comparative pharmacology of 705 EDRF and nitric oxide on vascular strips. Pharmacol 1987;141:445-51, 706 http://dx.doi.org/10.1016/0014-2999(87)90563-2. 707

39. Everett TR, Wilkinson IB, Mahendru AA, McEniery CM, Garner SF, 708 Goodall AH, et al. S-Nitrosoglutathione improves haemodynamics in 709 early-onset pre-eclampsia. Clin Pharmacol 2014;78:660-9, http:// 710 dx.doi.org/10.1111/bcp.12379.

40. Hasan AS, Socha M, Lamprecht A, Ghazouani FE, Sapin A, Hoffman 712 $\mathrm{M}$, et al. Effect of the microencapsulation of nanoparticles on the 713 reduction of burst release. Pharm 2007;344:53-61, http://dx.doi.org/ 714 10.1016/j.ijpharm.2007.05.066.

41. Seabra AB, De Oliveira MG. Poly(vinyl alcohol) and poly(vinyl 716 pyrrolidone) blended films for local nitric oxide release. Biomaterials 717 2004;25:3773-82, http://dx.doi.org/10.1016/j.biomaterials.2003.10.035. 718

42. Seabra AB, Fitzpatrick A, Paul J, De Oliveira MG, Weller R. Topically 719 applied $S$-nitrosothiol-containing hydrogels as experimental and phar- 720 macological nitric oxide donors in human skin. Dermatol 721 2004;151:977-83, http://dx.doi.org/10.1111/j.1365-2133.2004.06213.x. 722

43. George M, Abraham TE. Polyionic hydrocolloids for the intestinal 723 delivery of protein drugs: Alginate and chitosan - a review. J Control 724 Release 2006;114:1-14, http://dx.doi.org/10.1016/j.jconrel.2006.04.017. 725

44. Garrait G, Beyssac E, Subirade M. Development of a novel drug delivery 726 system: Chitosan nanoparticles entrapped in alginate microparticles. $J 727$ Microencapsul 2014;31:363-72, http://dx.doi.org/10.3109/ 728 02652048.2013 .858792

45. Bajka BH, Rigby NM, Cross KL, Macierzanka A, Mackie AR. The 730 influence of small intestinal mucus structure on particle transport ex vivo. 731 Colloids Surf B: Biointerfaces 2015;135:73-80, http://dx.doi.org/ 732 10.1016/j.colsurfb.2015.07.038.

46. Gaucher C, Boudier A, Dahboul F, Parent M, Leroy P. S-nitrosation/ 734 denitrosation in cardiovascular pathologies: Facts and concepts for the 735 rational design of $S$-nitrosothiols. Curr Pharm Des 2013;19:458-72. 736

47. Alencar JL, Lobysheva I, Geffard M, Sarr M, Schott C, Schini-Kerth 737 VB, et al. Role of $S$-nitrosation of cysteine residues in long-lasting 738 inhibitory effect of nitric oxide on arterial tone. Mol Pharmacol 739 $2003: 63: 1148-58$

48. Khan SI, Abourashed EA, Khan IA, Walker LA. Transport of harman 741 alkaloids across Caco-2 cell monolayers. Chem Pharm Bull 742 2004;52:394-7, http://dx.doi.org/10.1248/cpb.52.394.

49. Megson IL, Greig IR, Gray GA, Webb DJ, Butler AR. Prolonged effect of a 744 novel S-nitrosated glyco-amino acid in endothelium-denuded rat femoral 745 arteries: Potential as a slow release nitric oxide donor drug. Pharmacol 746 1997;122:1617-24, http://dx.doi.org/10.1038/sj.bjp.0701557. 747

50. Megson IL, Morton S, Greig IR, Mazzei FA, Field RA, Butler AR. N- 748 Substituted analogues of S-nitroso-N-acetyl-D, L-penicillamine: Chem- 749 ical stability and prolonged nitric oxide mediated vasodilatation in 750 isolated rat femoral arteries. Pharmacol 1999;126:639-48, http:// 751 dx.doi.org/10.1038/sj.bjp.0702346.

51. Nozik-Grayck E, Whalen EJ, Stamler JS, McMahon TJ, Chitano P, 753 Piantadosi CA. S-nitrosoglutathione inhibits alpha1-adrenergic receptor- 754 mediated vasoconstriction and ligand binding in pulmonary artery. 755 Physiol Lung Cell Mol Physiol 2006;290:L136-43, http://dx.doi.org/ 756 10.1152/ajplung.00230.2005. 
Nanomedicine: Nanotechnology, Biology, and Medicine $\mathrm{xx}(2016) \mathrm{xxx}-\mathrm{xxx}$ nanomedicine

Nanotechnology, Biology, and Medicine

Polymer nanocomposites enhance $S$-nitrosoglutathione intestinal absorption

Nanomedicine: Nanotechnology, Biology, and Medicine xxx (2016) xxx-xxx and promote the formation of releasable nitric oxide stores in rat aorta

Wen Wu, PharmD, PhD , Caroline Perrin-Sarrado, PharmD, $\mathrm{PhD}^{\mathrm{a}}$, Hui Ming, PharmD ${ }^{\mathrm{a}}$, Isabelle Lartaud, PharmD, $\mathrm{PhD}^{\mathrm{a}}$, Philippe Maincent, PharmD, $\mathrm{PhD}^{\mathrm{a}}$, Xian-Ming $\mathrm{Hu}, \mathrm{PhD}^{\mathrm{b}}$, Anne Sapin-Minet, $\mathrm{PhD}^{\mathrm{a}}$, Caroline Gaucher, $\mathrm{PhD}^{\mathrm{a}, *}$

${ }^{a}$ CITHEFOR EA3452 "Drug targets, formulation and preclinical assessment", Faculté de Pharmacie, Université de Lorraine, Nancy, France

${ }^{\mathrm{b}}$ State Key Laboratory of Virology, Ministry of Education Key Laboratory of Combinatorial Biosynthesis and Drug Discovery, Wuhan University School of Pharmaceutical Sciences, Wuhan, China

Novel alginate/chitosan nanocomposite particles were successfully developed for the delivery of $S$ nitrosoglutathione (GSNO), a physiological nitric oxide (NO) donor, with improved encapsulation efficiency, sustained-release. The developed nanocomposite particles enhanced intestinal absorption of GSNO and thus promoted the formation of NO stores in the blood vessels after oral administration to Wistar rats.

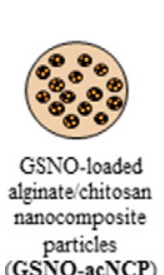

(GSNO-acNCP)

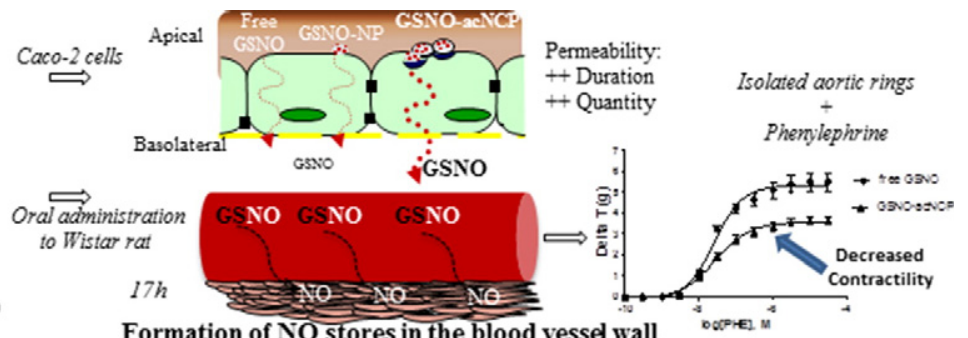

Formation of NO stores in the blood vessel wall 